\title{
Interval Cross Efficiency Measurement for General Two-Stage Systems
}

\author{
Abdol Hossein Tajik Yabr, ${ }^{1}$ Seyed Esmail Najafi $\left(\mathbb{D},{ }^{2}\right.$ Zohreh Moghaddas, ${ }^{3}$ \\ and Parisa Shahnazari Shahrezaei $\mathbb{D}^{4}$ \\ ${ }^{1}$ Department of Industrial Engineering, Central Tehran Branch, Islamic Azad University, Tehran, Iran \\ ${ }^{2}$ Department of Industrial Engineering, Science and Research Branch, Islamic Azad University, Tehran, Iran \\ ${ }^{3}$ Department of Mathematics, Ghazvin Branch, Islamic Azad University, Ghazvin, Iran \\ ${ }^{4}$ Department of Industrial Engineering, Firoozkooh Branch, Islamic Azad University, Firoozkooh, Iran
}

Correspondence should be addressed to Seyed Esmail Najafi; najafi1515@yahoo.com

Received 16 June 2021; Revised 5 November 2021; Accepted 28 December 2021; Published 28 February 2022

Academic Editor: Jianxu Liu

Copyright (c) 2022 Abdol Hossein Tajik Yabr et al. This is an open access article distributed under the Creative Commons Attribution License, which permits unrestricted use, distribution, and reproduction in any medium, provided the original work is properly cited.

\begin{abstract}
The data envelopment analysis (DEA), which is based on mathematical programming, is employed to measure the relative efficiency of several homogeneous decision-making units (DMUs) with multiple inputs and outputs. There has been extensive research on developing the classical DEA models for various forms and conditions. For example, ranking models such as cross efficiency have been proposed to address the shortcomings of the initial basic models. The data envelopment analysis for network systems has been developed as the network data envelopment analysis (NDEA), and models such as interval data envelopment analysis (IDEA) have been provided to take into account data uncertainty. But using this technique for issues that have all these conditions requires a single model, in which all the conditions are included. In the case study of this paper, the branches in the banking industry are ranked, and several models are presented according to different approaches to the NDEA in order to calculate the interval cross efficiency of a general two-stage network system. Finally, the results of the models are compared.
\end{abstract}

\section{Introduction}

The efficiency measurement or the data envelopment analysis (DEA) can well assess the efficiency of homogeneous units with the same input and outputs. The classical models proposed by Charnes, Cooper, and Rhodes [1] (CCR) and Banker, Charnes, and Cooper [2] (BCC) were immediately enhanced by researchers. The cross efficiency approach is provided to rank and address the shortcomings of the self-evaluation and nonuniqueness of optimum weights in the classical models. The network models are provided to calculate the efficiency of component divisions with internal processes and operations. There are also several models for ranking inaccurate and uncertain data, including interval, fuzzy, probability, and stochastic data. But ranking the units for issues that have all these conditions is not possible with the available models because such issues need a single model in which all these conditions are included. One of the applications of the DEA approach is in the banking industry. The banking process is a general two-stage network system. This system displays a high level of matching with the banking industry because of two levels of production and financial intermediation in banking procedures.

There is often no accurate data for real-world problems. Our data in the case study of this paper are interval. In addition, given that our goal is to rank the units and that there is no distinction between the efficient units in the CCR and BCC models, we suggested using the cross efficiency model. In this study, we will offer several models for combining the cross efficiency and network with interval data. The proposed models are based on different approaches presented to calculate the efficiency of general twostage systems. The scope of this paper on the DEA is shown in Figure 1. 


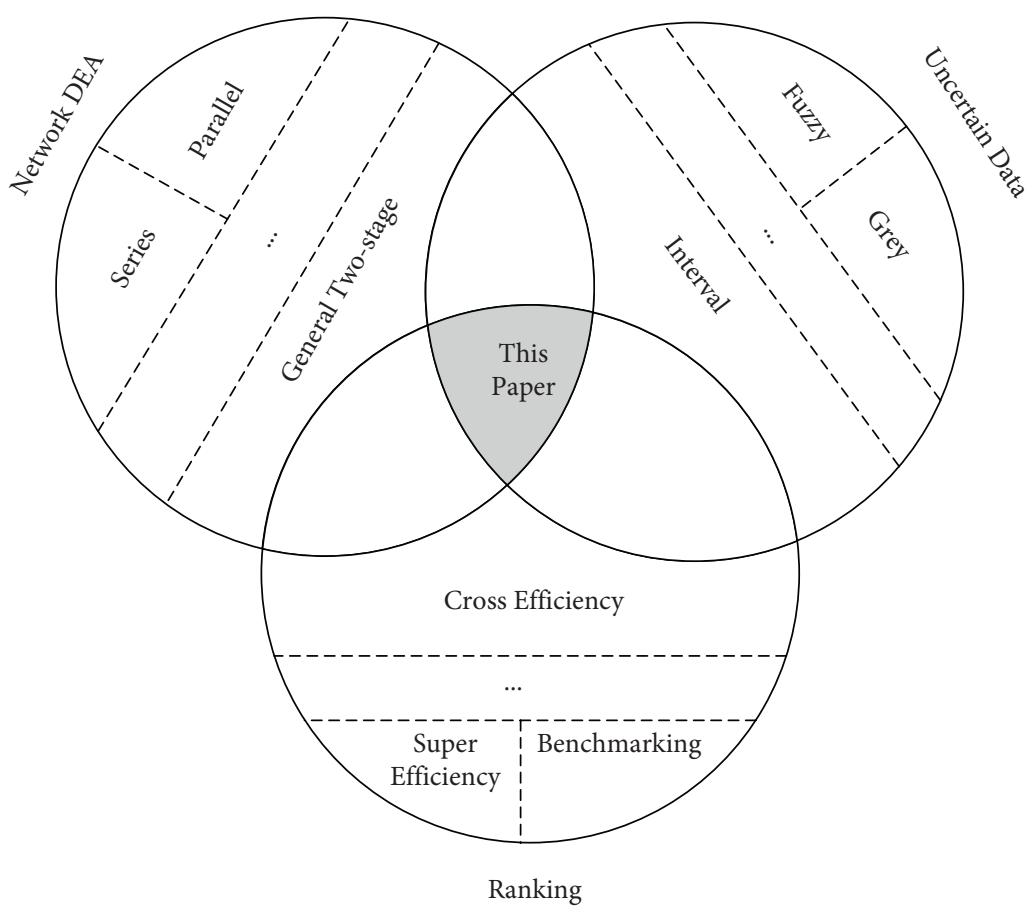

FIgURE 1: The scope of this paper on the DEA.

The models provided in this study will be validated based on a case study for ranking 17 branches of an Iranian bank. The rest of this study is organized as follows: In Section 2, the related research on the DEA, cross efficiency, network efficiency, and interval deficiency are reviewed. In Section 3, several models are offered to calculate the cross efficiency of the interval network. Section 4 is devoted to discussing the applications of the provided models in the banking industry in a case study. Finally, conclusions and suggestions are provided in Section 5.

\section{Literature Review}

The data envelopment analysis is linear and nonparametric programming for measuring the relative efficiency of a set of decision-making units with multiple inputs and outputs. To make decisions on the efficiency of a unit, it should be compared with its counterpart homogeneous units. A homogeneous unit is a unit with inputs and outputs similar to those in the other units under evaluation. Mentioning the difficulties in measuring the efficiency of units with multiple inputs and outputs, Farrell [3] for the first time introduced a method for measuring the efficiency of the agricultural section in America based on economic theories. Because of the practical problems and limitations of his method regarding the constant returns to scale, it did not find any practical application, and practical methods for measuring efficiency were introduced over time. One of these methods was the DEA introduced by Charnes, Cooper, and Rhodes [1] for measuring the relative efficiency of the national schools in America. This model was developed based on Farrell's definition of relative efficiency as the ratio of the sum of homogeneous outputs to inputs.
Consider $n$ units under homogeneous evaluation where $j$ indicates the number of units. Each unit has $m$ inputs and $s$ outputs. The inputs and outputs are represented by parameters $X_{i}$ and $Y_{r}$, respectively. For each input $X_{\mathrm{ij}}$, there is a variable weight $v_{i}$, and for each output $Y_{\mathrm{rj}}$, there is a variable weight $u_{r}$. The efficiency of $\mathrm{DMU}_{d}, d \epsilon j$, is denoted by $E_{d}$. Model (1) is a fractional CCR model with a constant return to scale, which can be transformed into linear model (2) through changing Charnes and Cooper's [4] variable. In all the fractional models, the denominator variables must be greater than a very small number $\varepsilon$ in order that the denominator not to be zero.

$$
\begin{aligned}
& E_{d}=\max \frac{\sum_{r=1}^{s} u_{r} Y_{\mathrm{rd}}}{\sum_{i=1}^{m} v_{i} X_{\mathrm{id}}}, \\
& \frac{\sum_{r=1}^{s} u_{r} Y_{\mathrm{rj}}}{\sum_{i=1}^{m} v_{i} X_{\mathrm{ij}}} \leq 1 \quad \forall j=1, \ldots, n, \quad \forall r=1, \ldots, s, \\
& u_{r} \geq 0 \quad \forall i=1, \ldots, m, \\
& v_{i} \geq \varepsilon \quad \sum_{r=1}^{s} u_{r} Y_{\mathrm{rd}}, \\
& E_{d}=\max , \quad \\
& \sum_{i=1}^{m} v_{i} X_{\mathrm{id}}=1, \quad \\
& \sum_{r=1}^{s} u_{r} Y_{\mathrm{rj}}-\sum_{i=1}^{m} v_{i} X_{\mathrm{ij}} \leq 0 \quad \forall j=1, \ldots, n, \\
& u_{r} \geq 0 \quad \forall r=1, \ldots, s, \\
& v_{i} \geq 0 \quad \forall i=1, \ldots, m .
\end{aligned}
$$


The mentioned model can be solved for any decisionmaking unit separately. The resultant efficiency is a figure ranging from 0 to 1 . If the unit is efficient, it means that it is present in the production possibility set and its efficiency is equal to 1 . Otherwise, the score given to an independent unit is less than 1 and below the production possibility set.

The classical models assign varying weights to the inputs and outputs for each DMU and maximize the efficiency of that unit. There are several problems in this respect. Firstly, the weights assigned to the inputs and outputs are not unique across the DMUs. In addition, the weights of some inputs or outputs may be approximated to be 0 , underestimating the inputs and outputs. Secondly, there is a lack of differentiation between the efficient units. The reason is the value of efficiency is equal to 1 , obtained for all the efficient units. Various ranking models have been offered to solve these problems. Hosseinzadeh Lotfi et al. [5] investigated and categorized all of the ranking methods. The super efficiency offered by Andersen and Petersen [6] and Mehrabian et al. [7], the common weight offered by Jahanshahloo et al. [8], the benchmarking offered by Sueyoshi [9], and the multicriteria decision-making offered by Li and Reeves [10] are among the famous models.

2.1. Cross Efficiency. The efficiency calculated by the classical models is commonly known as self-evaluation, in which each DMU with a favorite weight evaluates itself. If the efficiency of each DMU is calculated according to the favorite weights of other DMUs, another evaluation has occurred. The cross efficiency approach evaluates both the selfevaluation and the other evaluation if it is more reasonable and valid than the self-evaluation. This approach was first introduced by Sexton [11]. We have defined the cross efficiency of $\mathrm{DMU}_{d}$ as measured by $\mathrm{DMU}_{k}, k \in j$, as the ratio of the weighted output to the weighted input obtained when we use the input and output levels of $\mathrm{DMU}_{d}$ and the input and output weights derived for $\mathrm{DMU}_{k}$. $E_{\mathrm{dk}}$ is the entry in row $d$ and column $k$. Accordingly, the self-evaluations of the individual units are performed through model (2), and then each unit is evaluated considering the input and output weights of other units through equation (3). The matrix for the cross efficiency is formed and displayed in Table 1. Finally, the average linear efficiency of all the units is calculated, and the units are ranked from the highest value to the lowest one.

$$
E_{\mathrm{dk}}=\frac{\sum_{r=1}^{s} u_{r}^{k} Y_{\mathrm{rd}}}{\sum_{i=1}^{m} v_{i}^{k} X_{\mathrm{id}}}
$$

Although the cross efficiency approach has solved many problems of the earlier more common DEA, it has its own drawbacks as well, including: (1) the weights obtained by the CCR model are not unique, and the model has multiple answers; therefore, using each of these efficient weight sets to calculate the elements of the cross efficiency matrix will lead to the emergence of different values, and consequently, the calculated rankings through the cross efficiency are not unitary. (2) This evaluation is contradictory and imbalanced
TABle 1: Cross efficiency matrix.

\begin{tabular}{lccclc}
\hline & \multicolumn{5}{c}{ Rated $D M U_{k}$} \\
\\
\hline \multirow{2}{*}{ Rating } & 1 & $E_{11}$ & $E_{12}$ & $E_{1 k}$ & $E_{1 n}$ \\
$D M U_{d}$ & 2 & $E_{21}$ & $E_{22}$ & $\ldots$ & $E_{2 n}$ \\
& $\vdots$ & $E_{d 1}$ & $\vdots$ & $\vdots$ & $\vdots$ \\
& $n$ & $E_{n 1}$ & $E_{n 2}$ & $\ldots$ & $E_{n n}$ \\
\hline
\end{tabular}

because each DMU may determine a different total value (average value) in the other DMUs; that is, the DMUs with lower efficiencies than others have a more profound effect in the assessment of the cross efficiency, and vice versa. In other words, if we find the efficiencies of the DMUs based on the weights of a single inefficient DMU and sum them up, the calculated value will be larger than in the case where the efficiency of DMUs are calculated based on a single efficient DMU. Although we have adopted arithmetic average to calculate the cross efficiency based on the requirements of homogeneity of the DEA and have considered the same value for all the DMUs, not all of them have the same effect on the calculation of the final cross efficiency, that is, some DMUs are generous and some others are not. (3) Regarding the detachment of average weights [12], we can use range, median, variance, or other factors as well. (4) The average cross efficiency is not the same as the Pareto efficiency [13]. (5) The efficiency of self-evaluation, that is, the main diagonal of the matrix, is the major division of the assessment of cross efficiency [14], while the weights assigned to them are different across the DMUs. (6) The average cross efficiency does not represent the real performance of all the DMUs because it simply ignores the relative significance and sums them up equally [15]. (7) The self-evaluation efficiency cannot play an adequate role in the final and overall evaluations and rankings [16]. In the calculation of the linear average, we have considered equal values for all the elements, so that for the efficiency of self-evaluation, that is, the main diagonal of the matrix, we have considered $1 / n$ of a unit, and for another evaluation efficiency, $n-1 / n$ of a unit, which does not seem logical.

There are various methods for addressing the shortcomings of the cross efficiency approach, the most prominent of which is the concept of a secondary goal. The introduction of a secondary goal can be regarded as an opportunity to discover a more appropriate strategy to choose the weights that are closer to more suitable conditions. Using the functions of the secondary goal can resolve the nonuniqueness of the optimum weights. According to this concept, model (2) is solved in the first stage to calculate the efficiency of the DMU under evaluation. In the second stage, through solving another model, the unique weights can be found to calculate the cross efficiency. The second model can optimize the secondary goal if the efficiency remains at the calculated efficiency level through model (2). There have been various secondary goals. Doyle and Green [17] for the first time proposed two models for calculating efficiency: aggressive and benevolent. The benevolent model calculates the maximum efficiency for all the DMUs except for the DMU under evaluation if the efficiency of the DMU 
under evaluation remains at the CCR efficiency level. Another famous approach was introduced by Oral et al. [18]. They addressed optimizing the efficiency of $\mathrm{DMU}_{k}$ in the objective function if the $\mathrm{DMU}_{d}$ remains at the optimum value of $E_{d d}$. This approach is represented by model (4):

$$
\begin{aligned}
& E_{\mathrm{dk}}=\max \frac{\sum_{r=1}^{s} u_{r} Y_{\mathrm{rk}}}{\sum_{i=1}^{m} v_{i} X_{\mathrm{ik}}}, \\
& \frac{\sum_{r=1}^{s} u_{r} Y_{\mathrm{rd}}}{\sum_{i=1}^{m} v_{i} X_{\mathrm{id}}}=E_{\mathrm{dd}}, \\
& \frac{\sum_{r=1}^{s} u_{r} Y_{r j}}{\sum_{i=1}^{m} v_{i} X_{\mathrm{ij}}} \leq 1 \forall j=1, \ldots, n, \\
& u_{r} \geq 0 \quad \forall r=1, \ldots, s, \\
& v_{i} \geq \varepsilon \quad \forall i=1, \ldots, m .
\end{aligned}
$$

Carrillo and Jorge [19] offered a new approach to calculate cross efficiency. Their approach focuses on the calculation of the optimum weight for each DMU regardless of its effect on the evaluation of the other DMUs. They adopted the multicriteria decision analysis (MCDA) in some relationships to investigate the concept of ideal and nonideal units. Li et al. [20] offered a balanced approach to calculate cross efficiency. Initially, they offered a corrective measure to change the results of the traditional cross efficiency to a common and consistent evaluation standard for all the DMUs. They then offered a game-like iterative approach to obtain the optimal value for the balanced cross efficiency. Hou et al. [21] categorized the methods of resolving the problems about the cross efficiency emphasized by the researchers into two categories. The first category deals with the selection of competition and corporation, and the second one deals with the aggregation of cross efficiency matrix. After finding the ideal and nonideal points, they incorporated these points into the cross efficiency model, suggesting two models, the cross efficiency matrices of which would be their outputs. Finally, they transform these two matrices into an equation giving the arithmetic mean, geometric mean, and variance to calculate the final efficiency of each DMU. Ang et al. [22] introduced the concept of group cross efficiency by two definitions: the first is the average efficiency in which the group efficiency is calculated as the average of its members' efficiencies; the second one is the weakest efficiency in which the members' worst efficiency represents the group efficiency. Assuming that there is competition between the groups, their secondary goal minimizes the group efficiencies only if the efficiency of a specific group remains at the calculated value. The weights used in their model are common and show the uniform management of the central team. Consequently, they offered two group cross aggressive models. Kuang [23] investigated the efficiency of 18 railway bureaus using a combination of the super efficiency and cross efficiency approaches. Firstly, they obtained the ideal weight for each DMU through its super efficiency and then calculated the values of the cross efficiency matrix. Li et al. [24] offered a model for allocating the fixed cost to DMUs using a cooperative game and cross efficiency. In their approach, each DMU is considered as a player, and a superadditive characteristic function is defined for coalitions of the DMUs. All the DMUs have incentives to construct coalitions in order to increase their postallocation efficiencies. In a coalition, the inputs and outputs of the DMUs under evaluation are summed. Then, the Shapley value is calculated for each DMU, and accordingly, the associated common weights are optimized to determine the final allocation plan.

2.2. Network Data Envelopment Analysis. In the cross efficiency approach, many researchers regard the system as a whole unit despite the fact that many systems have internal structures and comprised interdependent components. Many studies such as Castelli et al. [25] and Kao and Hwang [26] have demonstrated that ignoring the operations of the component divisions can lead to misleading results. For example, a system may be efficient, while all the divisions are inefficient, or all the divisions in a DMU may have larger or equal efficiency to those of another, while the efficiency of the system is lower. Kao and Liu [27] offered a model for calculating the cross efficiency for the two series and parallel network systems.

Network systems can have different structures, including series, parallel, mixed, hierarchical, intermediate outputs, intermediate inputs, shared input, feedback, and so on, all of which are concepts with applications in the network data envelopment analysis (NDEA). Kao [28] has thoroughly covered the NDEA concepts. In section 11, he has addressed many approaches to calculating the efficiency in a general two-stage structure, which is employed in our models as well.

The general two-stage system discussed in this section has the structure shown in Figure 1, where stage 1 applies the exogenous inputs $X_{i}^{(1)}, i=1, \ldots, m(1)$ to produce the final outputs $Y_{r}^{(1)}, r=1, \ldots, s(1)$ and intermediate products $Z_{g}, g=1, \ldots, h$ and stage 2 applies the exogenous inputs $X_{i}^{(2)}, i=m(1)+1, \ldots, m$ and intermediate products $Z_{g}, g=1, \ldots, h$ to produce the final outputs $Y_{r}^{(2)}, r=S(1)+1, \ldots, s$. The efficiencies of stage 1, stage 2 , and system are denoted by $E_{d}^{(1)}, E_{d}^{(1)}$ and $E_{d}^{(T)}$, respectively. Regarding the structure shown in Figure 2, Kao [28] introduces the following methods to calculate efficiency. The simplest method is to use the arithmetic average of two divisions as the efficiency of the system.

Liang et al. [29] introduced the game approach, where two divisions or two players increase the efficiency of the system. Their approach can have two modes of cooperative and noncooperative. In the noncooperative mode, one of the divisions is a leader, and the other one is a follower. Here, if division $\mathrm{A}$ is the leader, then division $\mathrm{B}$ is the follower. First, the efficiency of division $A$ is calculated, and then the efficiency of division $B$ is derived by adding the constraint that the efficiency of division A remains at the previously calculated value. The system efficiency is calculated as follows:

$$
E_{d}^{(T)}=\frac{1}{2}\left(E_{d}^{(1)}+E_{d}^{(2)}\right) \text {. }
$$




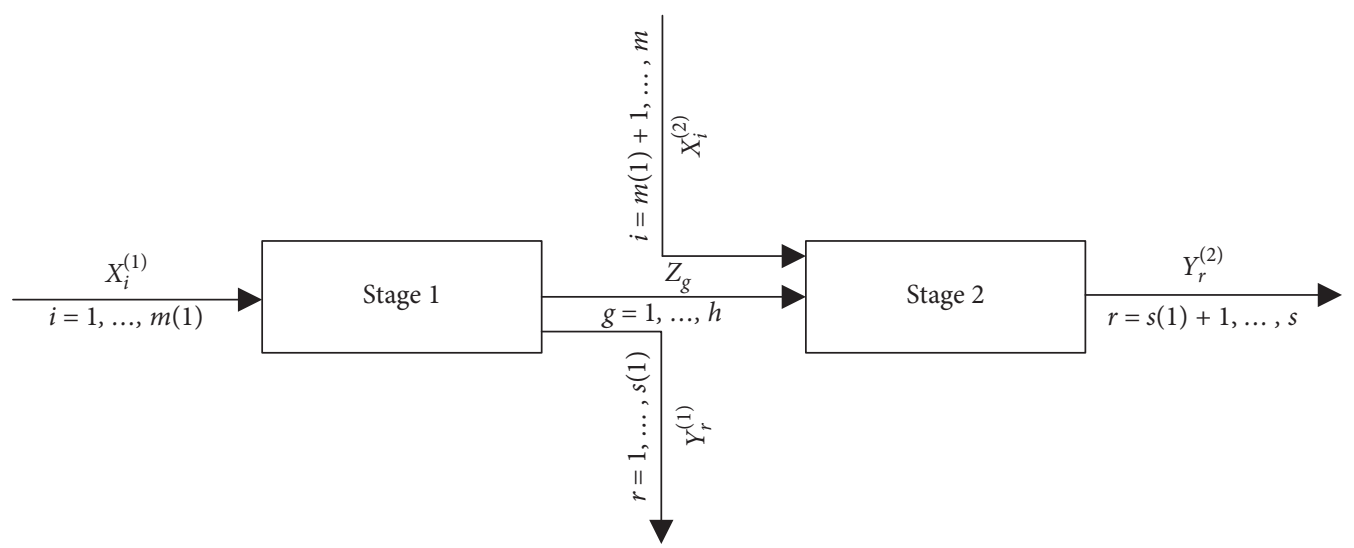

Figure 2: General two-stage system.

FathollahBayati and Sadjadi [30] developed the generalized NDEA models to examine the efficiency of two-tier suppliers under cooperative and noncooperative strategies where each tier has its own inputs/outputs and some outputs of the first tier can be fed back to the second tier.
If the two players or the two divisions cooperate with each other, the efficiency of the system is calculated by the use of a model, the objective function of which is as follows. Accordingly, the (average) efficiency of the two divisions is maximized only if the efficiency of each division does not exceed 1.

$$
E_{d}^{(T)}=\max \frac{1}{2}\left(\frac{\sum_{r=1}^{s(1)} u_{r} Y_{\mathrm{rd}}^{(1)}+\sum_{g=1}^{h} w_{g} Z_{\mathrm{gd}}}{\sum_{i=1}^{m(1)} v_{i} X_{\mathrm{id}}^{(1)}}+\frac{\sum_{r=s(1)+1}^{s} u_{r} Y_{\mathrm{rd}}^{(2)}}{\sum_{i=m(1)+1}^{m} v_{i} X_{\mathrm{id}}^{(2)}+\sum_{g=1}^{h} w_{g} Z_{\mathrm{gd}}}\right)
$$

Another approach considers the aggregation of efficiency, according to which, the system efficiency is calculated through the weighted average of the efficiencies of the divisions. The weight of each division is calculated using the ratio of the input of that division to the whole inputs of the system. After simplification and linearization, the objective function of the aggregation model is represented by the following equation:

$$
E_{d}^{(T)}=\max \sum_{r=1}^{s} u_{r} Y_{\mathrm{rd}}+\sum_{g=1}^{h} w_{g} z_{\mathrm{gd}}
$$

The objective function for a case where the efficiency of the system is obtained by multiplying the two divisions is presented by the following equation:

$$
E_{d}^{(T)}=\max \left(\frac{\sum_{r=1}^{s(1)} u_{r} Y_{\mathrm{rd}}^{(1)}+\sum_{g=1}^{h} w_{g} Z_{\mathrm{gd}}}{\sum_{i=1}^{m(1)} v_{i} X_{\mathrm{id}}^{(1)}} \times \frac{\sum_{r=s(1)+1}^{s} u_{r} Y_{\mathrm{rd}}^{(2)}}{\sum_{i=m(1)+1}^{m} v_{i} X_{\mathrm{id}}^{(2)}+\sum_{g=1}^{h} w_{g} Z_{\mathrm{gd}}}\right) .
$$

Khademi Zare et al. [31] presented a new robust twostage DEA for efficiency evaluation of the electricity power production and distribution companies. The robust optimization technique has been introduced for entering perturbation in mathematical programming problems such as two-stage DEA.

2.3. Interval Data Envelopment Analysis. In reality, many issues encounter data uncertainty. Interval data are the simplest type of uncertainty among fuzzy, probable, grey, and other types of data. Assuming that the inputs and outputs of a DMU are intervals, we represent them by $\left(X_{j}^{L}, X_{j}^{U}\right)\left(Y_{j}^{L}, Y_{j}^{U}\right)$, where indices $L$ and $U$ represent the lower and upper bounds, respectively. Calculation of a lower bound and an upper bound for the efficiency of a given DMU is as follows: $\left(E_{j}^{L}, E_{j}^{U}\right)$. Despotis and Smirlis [32] offered models (9) and (10) for the lower and upper bounds of the efficiency, respectively, assuming that the lower bound for a DMU occurs when it is in the worst condition and the other DMUs are in best conditions, and vice versa. It should be noted that a unit is in the best condition when it has the most outputs and the least inputs. 


$$
\begin{aligned}
& E_{d}^{L}=\max \frac{\sum_{r=1}^{s} u_{r} Y_{\mathrm{rd}}^{L}}{\sum_{i=1}^{m} v_{i} X_{\mathrm{id}}^{U}}, \\
& \frac{\sum_{r=1}^{s} u_{r} Y_{\mathrm{rd}}^{L}}{\sum_{i=1}^{m} v_{i} X_{\mathrm{id}}^{U}} \leq 1, \\
& \frac{\sum_{r=1}^{s} u_{r} Y_{\mathrm{rj}}^{U}}{\sum_{i=1}^{m} v_{i} X_{\mathrm{ij}}^{L}} \leq 1 \quad \forall j=1, \ldots, n, j \neq d, \\
& u_{r} \geq 0 \quad \forall r=1, \ldots, s, \\
& v_{i} \geq \varepsilon \quad \forall i=1, \ldots, m, \\
& E_{d}^{U}=\max _{r=1} \frac{\sum_{r}^{s} Y_{\mathrm{rd}}^{U}}{\sum_{i=1}^{m} v_{i} X_{\mathrm{id}}^{L}} \\
& \frac{\sum_{r=1}^{s} u_{r} Y_{\mathrm{rd}}^{U} \leq 1,}{\sum_{i=1}^{m}{ }_{v}^{i} X_{i d}^{L}} \leq 1, \\
& \frac{\sum_{r=1}^{s}{ }_{u}^{r} Y_{r j}^{L}}{\sum_{i=1}^{m} v_{i} X_{\mathrm{ij}}^{U}} \leq 1 \quad \forall j=1, \ldots, n, j \neq d, \\
& u_{r} \geq 0 \quad \forall r=1, \ldots, s, \\
& v_{i} \geq \varepsilon \quad \forall i=1, \ldots, n .
\end{aligned}
$$

So far, some combinations of different methods have been developed, including the interval cross efficiency and the interval analytic hierarchy models by Akbarian [33], the dynamic double frontier MDEA model with interval type- 2 fuzzy data by Zhou et al. [34], the two-stage NDEA model under interval data by Seyed Esmaeili et al. [35], and the cross efficiency evaluation and ranking method based on interval data by $\mathrm{Yu}$ et al. [36].

\section{Methodology}

In this section, several models are offered to calculate the network interval cross efficiency. We offer the models based on the combination of several approaches such as the approach of Oral et al. [18] for cross efficiency and that of Despotis and Smirlis [32] for interval efficiency. There are also other approaches including an approach to calculate the network efficiency for a general twostage case such as calculating the system efficiency as the average of two divisions, the noncooperative game approach (leader and follower), the cooperative game approach, the efficiency aggregation approach for the additive form, and the efficiency aggregation approach for the multiplicative form mentioned in the previous section. Consider the network structure shown in Figure 2 and known as the general two-stage structure.

Initially, we need to calculate the lower and upper bounds of each division for all the DMUs. Table 2 represents the models needed to calculate the lower-bound efficiency of the two divisions in the fractional and linear modes. In the fractional mode, the goal can be achieved when $\mathrm{DMU}_{d}$ is in the worst condition, that is, having the least output and the most input. The first constraint ensures that all the DMUs are in the best conditions and the maximum efficiency value is 1 , and the second constraint ensures that the maximum efficiency value for $\mathrm{DMU}_{d}$ is 1 . To prevent multiplicity of models, in all the models that are going to be presented in the rest of the paper, it suffices to offer the model for calculating the lower bound. Calculating the upper bound of the cross efficiency is possible by changing the upper bounds to the lower bounds, and vice versa.

3.1. Interval Cross Efficiency of a General Two-Stage Network System: Average of Two-Division Approach. In this case, the upper and lower bounds of the cross efficiency of the two divisions are calculated separately, and then the efficiency of the system is assessed using the arithmetic average. The models for calculating the lower bound of cross efficiency of both the divisions and system in both the fractional and linear modes are depicted in Table 3. In the fractional mode, the goal can be achieved only if $\mathrm{DMU}_{k}$ is in the worst condition, that is, the least output and the most input. The first constraint ensures that optimal weights are achieved when the efficiency value of $\mathrm{DMU}_{d}$ is the same as the calculated value as in Table 2. The second constraint ensures that the other DMUs except for indices $k$ and $d$ are in the best conditions and the maximum value of efficiency is 1 . The third constraint ensures that the maximum efficiency value of $\mathrm{DMU}_{k}$ is 1 .

3.2. Cross Efficiency of a General Two-Stage Network System: Noncooperative Game Approach. Assuming that both the divisions are increasing the efficiency of the system without cooperation, one of them should initially calculate its own efficiency as the leader, and then the second division calculates its own efficiency as a follower only if the efficiency of the leader division remains the same throughout the calculations. Table 4 illustrates the models for calculating the lower bound of cross efficiency for the follower division in the fractional and linear modes as well as the efficiency of the system. The values for the lower bound of the cross efficiency for the leader division are computed as in Table 3. The description of the proposed model is similar to that of the other divisions, while three constraints are added to the model in order to keep constant the efficiency value of the leader division in the calculated value and prevent other DMUs in the leader division from exceeding 1.

\subsection{Interval Cross Efficiency of the General Two-Stage Network} System: Cooperative Game Approach. Assuming that the two divisions are increasing the efficiency of the system with cooperation; initially, the lower bounds of the efficiency values of all the DMUs are calculated using model (11), and then the lower bound of the cross efficiency is calculated using model (12). The purpose of model (12) is to maximize the arithmetic average of the efficiencies of $\mathrm{DMU}_{k}$ only if the efficiency of $\mathrm{DMU}_{d}$ remains the same as in model (11) and 


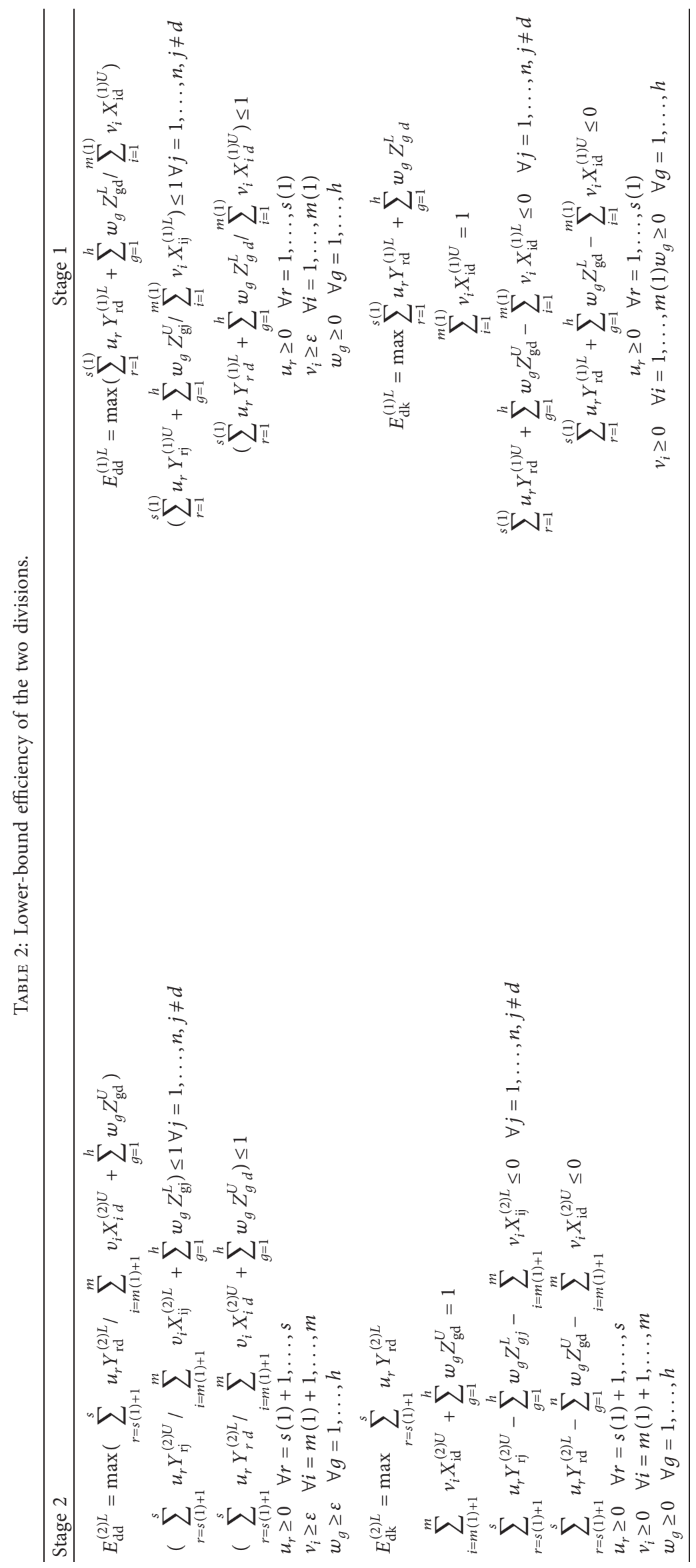




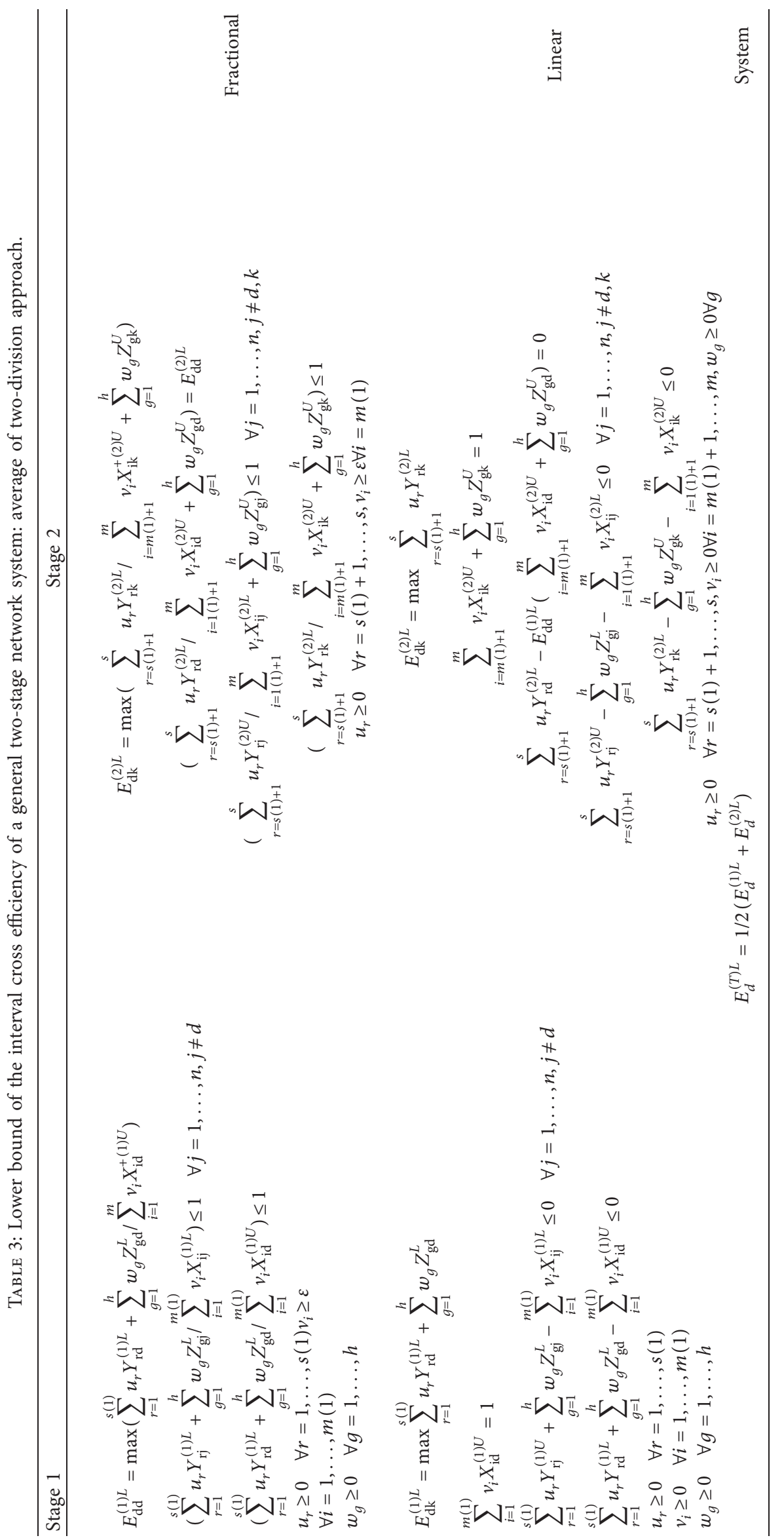




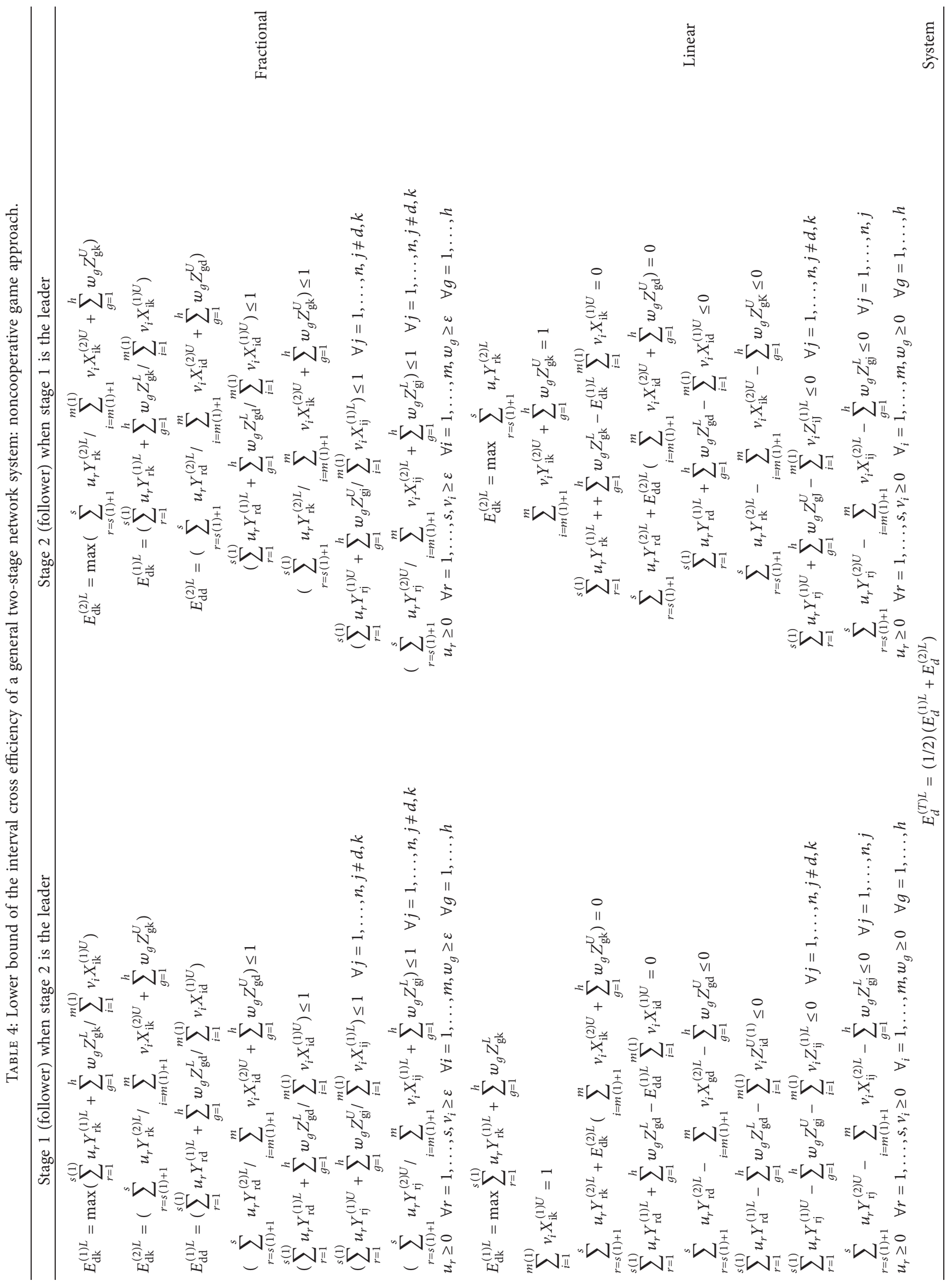


the efficiencies of the individual divisions for all the DMUs do not exceed 1. Although some of the constraints of the model are linearized for simplifying the computations, the model is nonlinear.

$$
\begin{aligned}
& E_{\mathrm{dd}}^{(T) L}=\max \frac{1}{2}\left(\frac{\sum_{r=1}^{s(1)} u_{r} Y_{\mathrm{rd}}^{(1) L}+\sum_{g=1}^{h} w_{g} Z_{\mathrm{gd}}^{L}}{\sum_{i=1}^{m(1)} v_{i} X_{\mathrm{id}}^{(1) U}}+\frac{\sum_{r=s(1)+1}^{s} u_{r} Y_{\mathrm{rd}}^{(2) L}}{\sum_{i=m(1)+1}^{m} v_{i} X_{\mathrm{id}}^{(2) U}+\sum_{g=1}^{h} w_{g} Z_{\mathrm{gd}}^{U}}\right), \\
& \sum_{r=1}^{s(1)} u_{r} Y_{\mathrm{rj}}^{(1) U}+\sum_{g=1}^{h} w_{g} Z_{\mathrm{g} j}^{U}-\sum_{i=1}^{m(1)} v_{i} X_{i j}^{(1) L} \leq 0 \forall j=1, \ldots, n, j \neq d, \\
& \sum_{r=s(1)+1}^{s}{ }_{u}^{r} Y_{r j}^{(2) U}-\sum_{i=m(1)+1}^{m}{ }_{v}^{i} X_{\mathrm{ij}}^{(2) L}-\sum_{g=1}^{h} w_{g} Z_{\mathrm{gj}}^{L} \leq 0 \quad \forall j=1, \ldots, n, j \neq d, \\
& \sum_{r=1}^{s(1)} u_{r} Y_{\mathrm{rd}}^{(1) L}+\sum_{g=1}^{h} w_{g} Z_{\mathrm{gd}}^{L}-\sum_{i=1}^{m(1)} v_{i} X_{\mathrm{id}}^{(1) U} \leq 0 \\
& \sum_{r=s(1)+1}^{s} u_{r} Y_{\mathrm{rd}}^{(2) L}-\sum_{i=m(1)+1}^{m} v_{i} X_{\mathrm{id}}^{(2) U}-\sum_{g=1}^{h} w_{g} Z_{\mathrm{gd}}^{U} \leq 0 \\
& u_{r} \geq 0 \quad \forall r=1, \ldots, s, \\
& v_{i} \geq \mathcal{E} \quad \forall i=1, \ldots, m, \\
& w_{g} \geq \varepsilon \quad \forall g=1, \ldots, h \text {, } \\
& E_{\mathrm{dk}}^{(T) L}=\max \frac{1}{2}\left(\frac{\sum_{r=1}^{s(1)} u_{r} Y_{\mathrm{rk}}^{(1) L}+\sum_{g=1}^{h} w_{g} Z_{\mathrm{gk}}^{L}}{\sum_{i=1}^{m(1) i}{ }_{v} X_{i k}^{(1) U}}+\frac{\sum_{r=s(1)+1}^{s} u_{r} Y_{\mathrm{rk}}^{(2) L}}{\sum_{i=m(1)+1}^{m} v_{i} X_{\mathrm{ik}}^{(2) U}+\sum_{g=1}^{h} w_{g} Z_{\mathrm{gk}}^{U}}\right), \\
& \frac{1}{2}\left(\frac{\sum_{r=1}^{s(1)} u_{r} Y_{\mathrm{rd}}^{(1) L}+\sum_{g=1}^{h} w_{g} Z_{\mathrm{gd}}^{L}}{\sum_{i=1}^{m(1)} v_{i} X_{\mathrm{id}}^{(1) U}}+\frac{\sum_{r=s(1)+1}^{s} u_{r d}^{r} Y_{r=1}^{(2) L}}{\sum_{i=m(1)+1}^{m} v_{i} X_{\mathrm{id}}^{(2) U}+\sum_{g=1}^{h} w_{g} Z_{\mathrm{gd}}^{U}}\right)=E_{\mathrm{dd}}^{(T) L}, \\
& \sum_{r=1}^{s(1)} u_{r} Y_{\mathrm{rj}}^{(1) U}+\sum_{g=1}^{h} w_{g} Z_{\mathrm{gj}}^{U}-\sum_{i=1}^{m(1)} v_{i} X_{\mathrm{ij}}^{(1) L} \leq 0 \quad \forall j=1, \ldots, n, j \neq d, k, \\
& \sum_{r=1}^{s(1)} u_{r} Y_{\mathrm{rk}}^{(1) L}+\sum_{g=1}^{h} w L_{g} Z_{\mathrm{gk}}^{L}-\sum_{i=1}^{m(1)} v_{i} X_{\mathrm{ik}}^{(1) U} \leq 0 \\
& \sum_{r=s(1)+1}^{s} u_{r} Y_{\mathrm{rj}}^{(2) U}-\sum_{i=m(1)+1}^{m} v_{i} X_{\mathrm{ij}}^{(2) L}-\sum_{g=1}^{h} w_{g} Z_{\mathrm{gj}}^{L} \leq 0 \quad \forall j=1, \ldots, n, j \neq d, k, \\
& \sum_{r=s(1)+1}^{s} u_{r} Y_{\mathrm{rk}}^{(2) L}-\sum_{i=m(1)+1}^{m} v_{i} X_{\mathrm{ik}}^{(2) U}-\sum_{g=1}^{h} w_{g} Z_{\mathrm{gk}}^{U} \leq 0, \\
& \sum_{r=1}^{s(1)} u_{r} Y_{\mathrm{rd}}^{(1) L}+\sum_{g=1}^{h} w_{g} Z_{\mathrm{gd}}^{L}-\sum_{i=1}^{m(1)} v_{i} X_{\mathrm{id}}^{(1) U} \leq 0, \\
& \sum_{r=s(1)+1}^{s} u_{r} Y_{\mathrm{rd}}^{(2) L}-\sum_{i=m(1)+1}^{m} v_{i} X_{\mathrm{id}}^{(2) U}-\sum_{g=1}^{h} w_{g} Z_{\mathrm{gd}}^{U} \leq 0, \\
& u_{r} \geq 0 \quad \forall r=1, \ldots, s \text {, } \\
& v_{i} \geq \varepsilon \quad \forall i=1, \ldots, m, \\
& w_{g} \geq \varepsilon \quad \forall g=1, \ldots, h \text {. }
\end{aligned}
$$


3.4. Interval Cross Efficiency of the General Two-Stage Network System: Aggregation Approach of Additive Form. According to this approach, the efficiency of the system is maximized only if the efficiency of all the divisions does not exceed 1. Initially, the network interval efficiency is calculated as in Table 5, and then the cross efficiency is derived. The models for calculating the efficiency of the lower bound of cross efficiency in fractional and linear forms are illustrated in Table 6. Accordingly, the efficiency is considered as the ratio of the sum of all the outputs of the divisions to the sum of all the inputs of them. The purpose of the fractional model as in Table 6 is to increase the efficiency of $\mathrm{DMU}_{k}$ only if the efficiency of $\mathrm{DMU}_{d}$ remains the same as in the calculations in Table 5 and the efficiency of the individual divisions does not exceed 1 for all the DMUs.
3.5. Interval Cross Efficiency of the General Two-Stage Network System: Aggregation Approach of Multiplicative Form. Similar to the last approach, in this approach, the efficiency of the system is maximized only if the efficiency of the divisions does not exceed 1, while the system efficiency is calculated by multiplying the efficiency of the divisions. Initially, the interval network efficiency is calculated based on model (13), and then the cross efficiency is derived by model (14). The purpose of model (14) is to increase the efficiency of $\mathrm{DMU}_{k}$ only if the efficiency of $\mathrm{DMU}_{d}$ remains the same as in model (13) and the efficiency of the individual divisions for all the DMUs does not exceed 1. Although some of the constraints are linearized for simplifying the computations, the model is nonlinear.

$$
\begin{aligned}
& E_{\mathrm{dd}}^{(T) L}=\max \left(\frac{\sum_{r=1}^{s(1)} u_{r} Y_{\mathrm{rd}}^{(1) L}+\sum_{g=1}^{h} w_{g} Z_{\mathrm{gd}}^{L}}{\sum_{i=1}^{m(1)} v_{i} X_{\mathrm{id}}^{(1) U}} \times \frac{\sum_{r=s(1)+1}^{s} u_{r} Y_{\mathrm{rd}}^{(2) L}}{\sum_{i=m(1)+1}^{m} v_{i} X_{\mathrm{id}}^{(2) U}+\sum_{g=1}^{h} w_{g} Z_{\mathrm{gd}}^{U}}\right), \\
& \sum_{r=1}^{s(1)} u_{r} Y_{\mathrm{rd}}^{(1) L}+\sum_{g=1}^{h} w_{g} Z_{\mathrm{gd}}^{L}-\sum_{i=1}^{m(1)} v_{i} X_{\mathrm{id}}^{(1) U} \leq 0, \\
& \sum_{r=s(1)+1}^{s} u_{r} Y_{\mathrm{rd}}^{(2) L}-\sum_{i=m(1)+1}^{m} v_{i} X_{\mathrm{id}}^{(2) U}-\sum_{g=1}^{h} w_{g} Z_{\mathrm{gd}}^{U} \leq 0 \\
& \sum_{r=1}^{s(1)} u_{r} Y_{\mathrm{rj}}^{(1) U}+\sum_{g=1}^{h} w_{g} Z_{\mathrm{gj}}^{U}-\sum_{i=1}^{m(1)} v_{i} X_{\mathrm{ij}}^{(1) L} \leq 0 \quad \forall j=1, \ldots, n, j \neq d, \\
& \sum_{r=s(1)+1}^{s} u_{r} Y_{\mathrm{rj}}^{(2) U}-\sum_{i=m(1)+1}^{m} v_{i} X_{\mathrm{ij}}^{(2) L}-\sum_{g=1}^{h} w_{g} Z_{\mathrm{gj}}^{L} \leq 0 \quad \forall j=1, \ldots, n, j \neq d, \\
& u_{r} \geq 0 \quad, v_{i} \geq \varepsilon, w_{g} \geq \varepsilon \\
& E_{\mathrm{dk}}^{(T) L}=\max \left(\frac{\sum_{r=1}^{s(1)} u_{r} Y_{\mathrm{rk}}^{(1) L}+\sum_{g=1}^{h} w_{g} Z_{\mathrm{gk}}^{L}}{\sum_{i=1}^{m(1)} v_{i} X_{\mathrm{ik}}^{(1) U}} \times \frac{\sum_{r=s(1)+1}^{s} u_{r} Y_{\mathrm{rk}}^{(2) L}}{\sum_{i=m(1)+1}^{m} v_{i} X_{\mathrm{ik}}^{(2) U}+\sum_{g=1}^{h} w_{g} Z_{\mathrm{gk}}^{U}}\right) \text {, } \\
& E_{\mathrm{dd}}^{(T) L}=\frac{\sum_{r=1}^{s(1)} u_{r} Y_{\mathrm{rd}}^{(1) L}+\sum_{g=1}^{h} w_{g} Z_{\mathrm{gd}}^{L}}{\sum_{i=1}^{m(1)} v_{i} X_{\mathrm{id}}^{(1) U}} \times \frac{\sum_{r=s(1)+1}^{s} u_{r} Y_{\mathrm{rd}}^{(2) L}}{\sum_{i=m(1)+1}^{m} v_{i} X_{\mathrm{id}}^{(2) U}+\sum_{g=1}^{h} w_{g} Z_{\mathrm{gd}}^{U}}, \\
& \sum_{r=1}^{s(1)} u_{r} Y_{\mathrm{rd}}^{(1) L}+\sum_{g=1}^{h} w_{g} Z_{\mathrm{gd}}^{L}-\sum_{i=1}^{m(1)} v_{i} X_{\mathrm{id}}^{(1) U} \leq 0 \\
& \sum_{r=s(1)+1}^{s} u_{r} Y_{\mathrm{rd}}^{(2) L}-\sum_{i=m(1)+1}^{m} v_{i} X_{\mathrm{id}}^{(2) U}-\sum_{g=1}^{h} w_{g} Z_{\mathrm{gd}}^{U} \leq 0, \\
& \sum_{r=1}^{s(1)} u_{r} Y_{\mathrm{rk}}^{(1) L}+\sum_{g=1}^{h} w_{g} Z_{\mathrm{gk}}^{L}-\sum_{i=1}^{m(1)} v_{i} X_{\mathrm{ik}}^{(1) U} \leq 0
\end{aligned}
$$




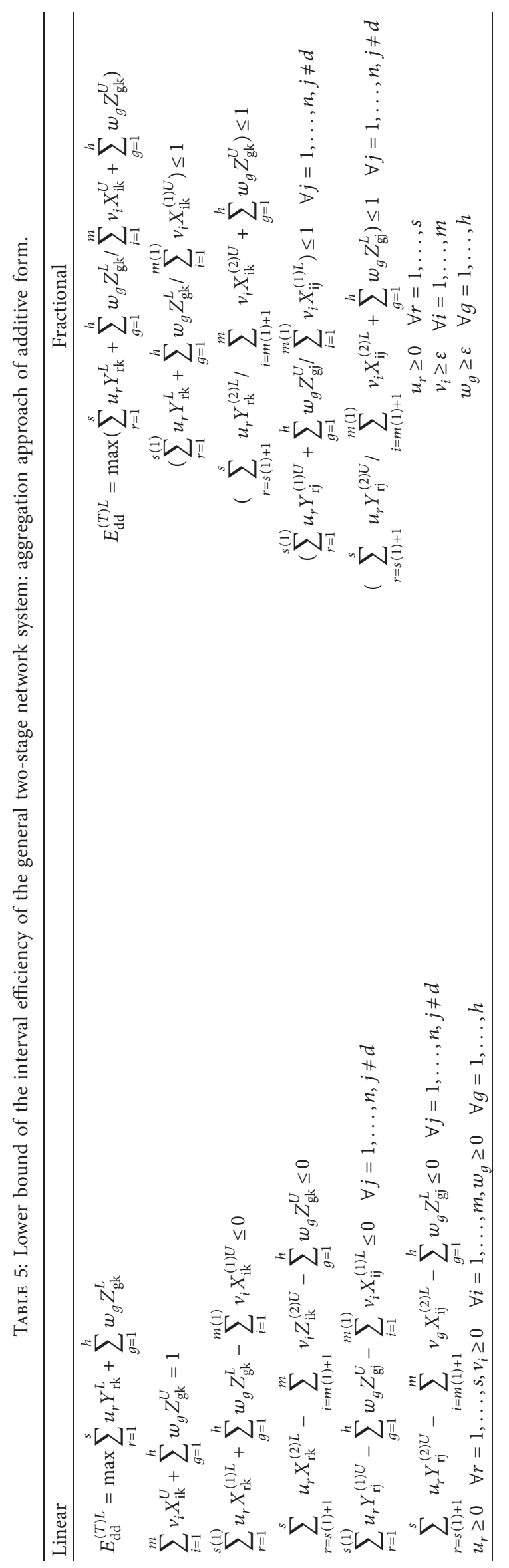




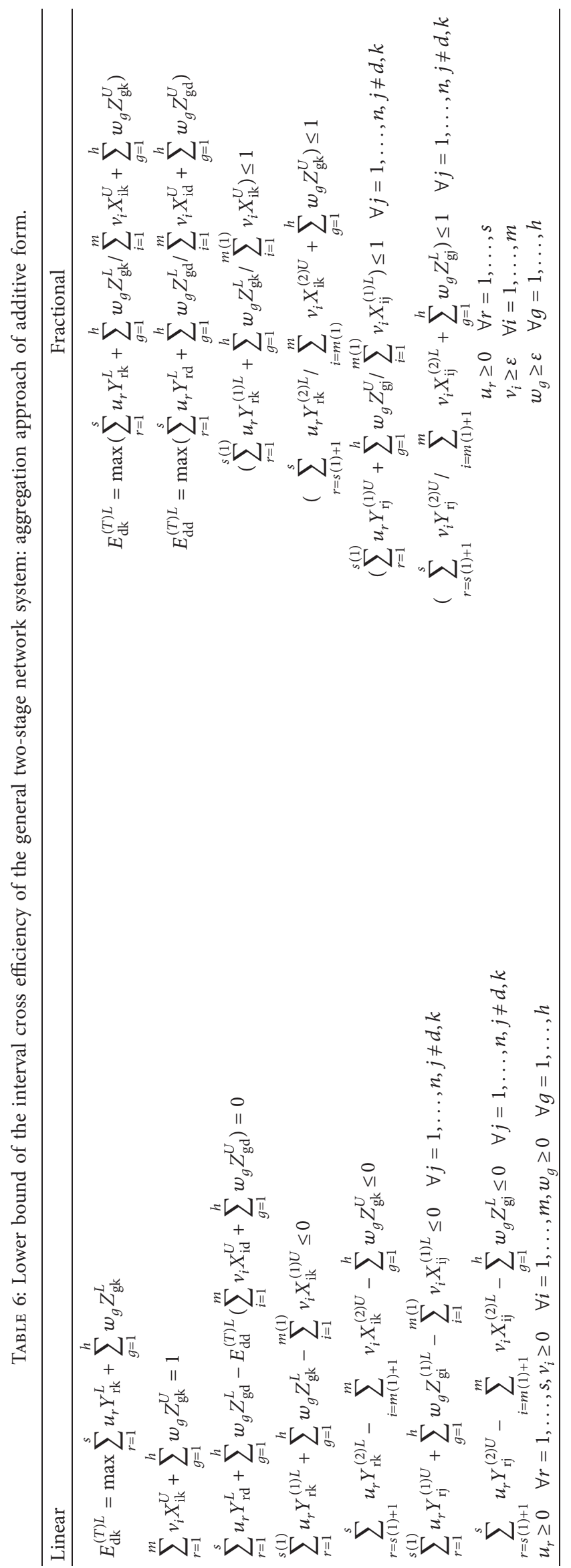




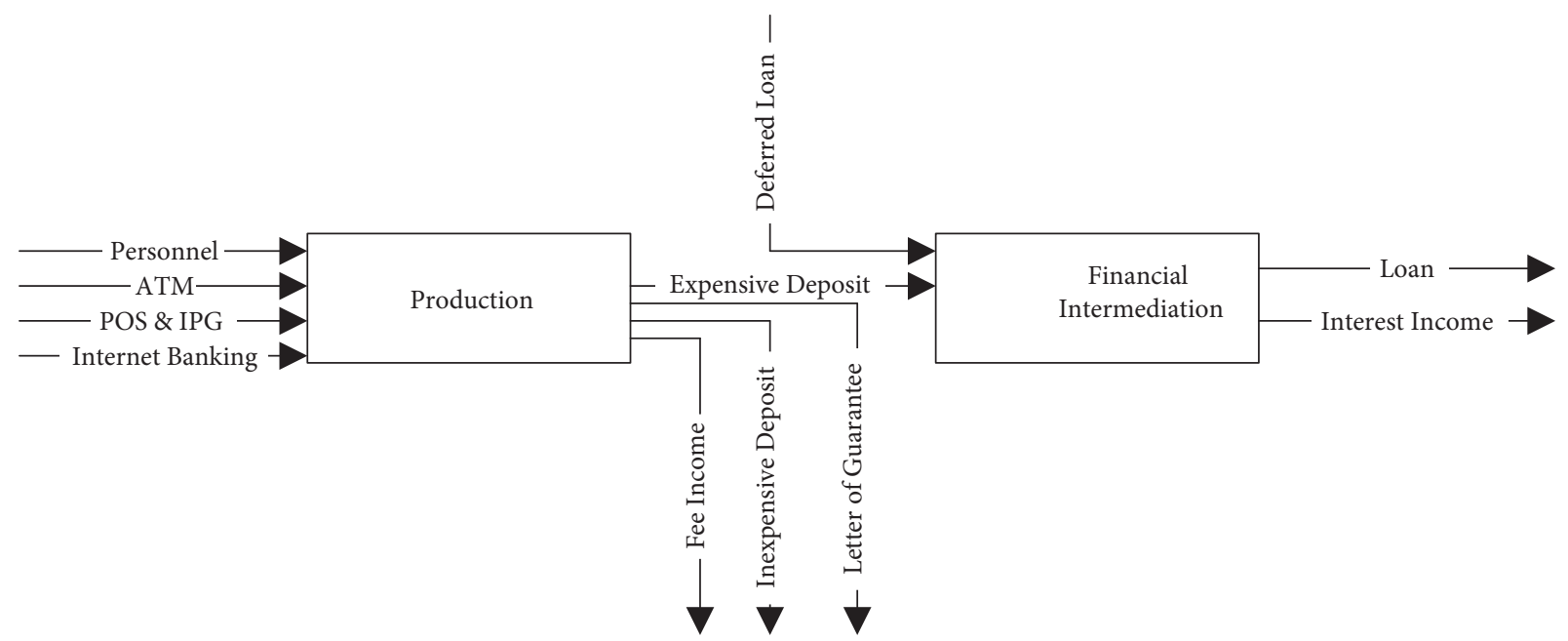

FIgURE 3: The network system of banking procedure.

$$
\begin{aligned}
& \sum_{r=s(1)+1}^{s} u_{r} Y_{\mathrm{rk}}^{(2) L}-\sum_{i=m(1)+1}^{m} v_{i} X_{\mathrm{ik}}^{(2) U}-\sum_{g=1}^{h} w_{g} Z_{\mathrm{gk}}^{U} \leq 0, \\
& \sum_{r=1}^{s(1)} u_{r} Y_{\mathrm{rj}}^{(1) U}+\sum_{g=1}^{h} w_{g} Z_{\mathrm{gj}}^{U}-\sum_{i=1}^{m(1)} v_{i} X_{\mathrm{ij}}^{(1) L} \leq 0 \quad \forall j=1, \ldots, n, j \neq d, k, \\
& \sum_{r=s(1)+1}^{s} u_{r} Y_{\mathrm{rj}}^{(2) U}-\sum_{i=m(1)+1}^{m} v_{i} X_{\mathrm{ij}}^{(2) L}-\sum_{g=1}^{h} w_{g} Z_{\mathrm{gj}}^{L} \leq 0 \quad \forall j=1, \ldots, n, j \neq d, k, \\
& u_{r} \geq 0, v_{i} \geq \varepsilon, w_{g} \geq \varepsilon .
\end{aligned}
$$

\section{Example}

In this section, the models offered in the last sections are evaluated through a case study. The efficiency measurement is regarded as an application of the DEA approach in the banking industry. As stated in earlier research, the banking procedure is a two-stage process with two divisions of production and financial intermediation. In the production division, financial institutions absorb capital to allocate loans. Financial institutions are thought of as primarily producing services for account holders. They perform transactions and process documents for customers, including loan applications, credit reports, checks or other payment instruments, and insurance policy or claim forms [37]. The benefit gained through this stage is known as fee income. In the financial intermediation stage, financial institutions are thought of as primarily intermediating funds between savers and investors. The financial resources gained through the first-stage are granted to investors in the form of loans with higher interest rates than the interest given to depositors. The interest gained through this stage is called net interest income. Net interest income is defined as the difference between the interest income a bank earns from loans and other interest-bearing securities and the interest expense it pays to borrow funds, deposits, and other borrowings.
Since the personnel, the automated teller machine (ATM), the point of sale (POS), the internet payment gateway (IPG), and internet banking demand their own costs and service revenues are earned through them, they are considered as the first-stage inputs. Because fee income, letter of guarantee, and inexpensive deposits are profitable for the bank, they are considered as first-stage outputs. The deferred loan of the bank, defined as the product of financial intermediation processes, decreasing the value of which is sought by the bank, is considered as the second-stage input. The amount of loans and net interest incomes are considered as the second-stage outputs, and the bank gains profit out of increasing their values. Expensive deposits are a source of loss to the bank because they receive interest from the bank. On the other hand, these deposits are a good source for loan payments, from which banks gain profits. Therefore, in some researches, they are considered as the input and, in some others, as the output. An advantage of network systems is parameter definition for both input and output nature. We have considered the expensive deposits as the first-stage output and the second-stage input. Overall, the banking procedure can be illustrated as a general two-stage process with middle inputs and outputs as in Figure 3.

The input and output values related to 17 branches of an Iranian bank in Tehran were investigated during a one-year period, and the minimum and maximum values were 


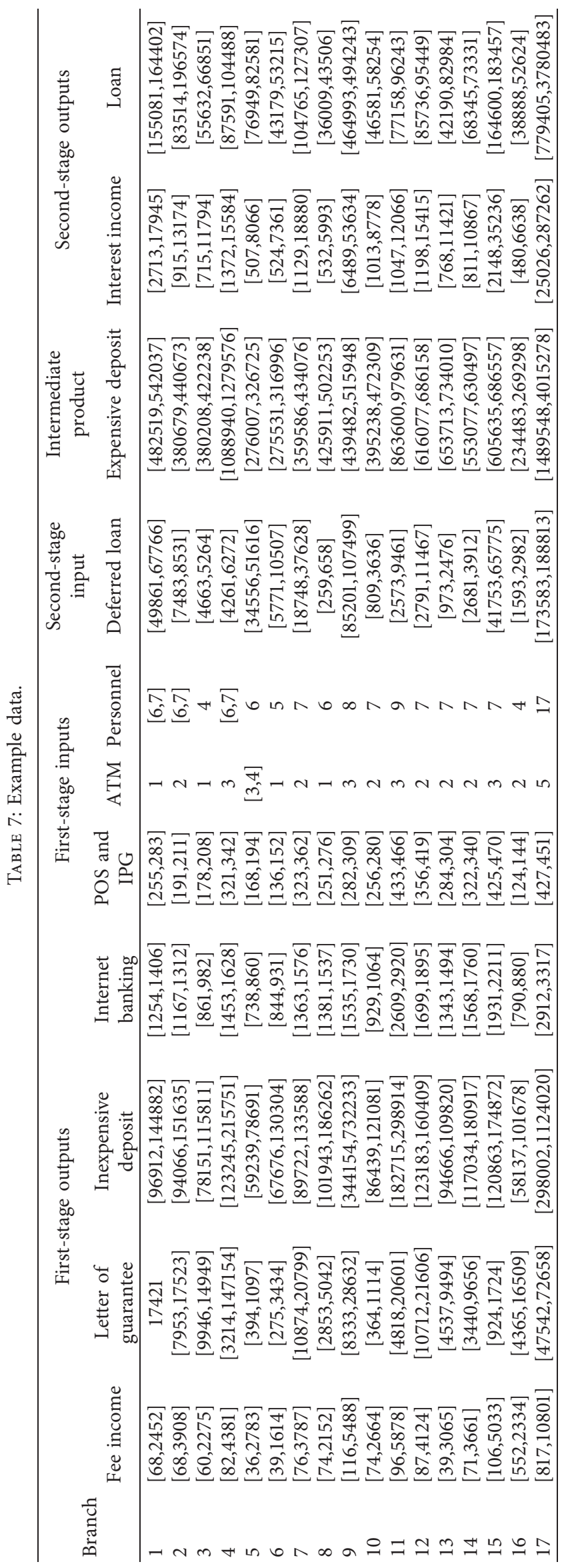


TABLE 8: Efficiency values and rankings calculated through different approaches.

\begin{tabular}{lcccccccccccc}
\hline \multirow{3}{*}{$\begin{array}{c}\text { Branch } \\
\end{array}$} & \multicolumn{3}{c}{ Interval network efficiency } & \multicolumn{4}{c}{ Average of two-division approach } & \multicolumn{3}{c}{ Noncooperative game approach. Stage 1 is } \\
& Rank & System & Stage 2 & Stage 1 & Rank & System & Stage 2 & Stage 1 & Rank & System & Stage 2 & Stage 1 \\
\hline 1 & 6 & 0.703 & {$[0.113,1]$} & {$[0.699,1]$} & 15 & 0.583 & {$[0,0.0989]$} & {$[0.342,1]$} & 15 & 0.604 & {$[0.083,0.989]$} & {$[0.342,1]$} \\
2 & 13 & 0.654 & {$[0.372,1]$} & {$[0.243,1]$} & 16 & 0.578 & {$[0,0.980]$} & {$[0.33,1]$} & 11 & 0.649 & {$[0.285,0.980]$} & {$[0.33,1]$} \\
3 & 5 & 0.717 & {$[0.361,1]$} & {$[0.508,1]$} & 14 & 0.584 & {$[0,0.996]$} & {$[0.346,0.995]$} & 6 & 0.656 & {$[0.288,0.996]$} & {$[0.346,0.995]$} \\
4 & 4 & 0.747 & {$[0.330,1]$} & {$[0.659,1]$} & 13 & 0.594 & {$[0.019,1]$} & {$[0.360,0.997]$} & 2 & 0.661 & {$[0.285,1]$} & {$[0.360,0.997]$} \\
5 & 17 & 0.581 & {$[0.093,1]$} & {$[0.233,1]$} & 4 & 0.651 & {$[0.329,1]$} & {$[0.274,1]$} & 16 & 0.590 & {$[0.086,1]$} & {$[0.274,1]$} \\
6 & 14 & 0.629 & {$[0.171,1]$} & {$[0.343,1]$} & 1 & 0.670 & {$[0.329,1]$} & {$[0.350,1]$} & 5 & 0.658 & {$[0.281,1]$} & {$[0.350,1]$} \\
7 & 16 & 0.594 & {$[0.126,1]$} & {$[0.249,1]$} & 2 & 0.663 & {$[0.329,0.967]$} & {$[0.355,1]$} & 10 & 0.650 & {$[0.279,0.967]$} & {$[0.355,1]$} \\
8 & 2 & 0.793 & {$[0.642,1]$} & {$[0.530,1]$} & 12 & 0.609 & {$[0.129,0.949]$} & {$[0.357,1]$} & 14 & 0.622 & {$[0.133,1]$} & {$[0.357,1]$} \\
9 & 3 & 0.751 & {$[0.355,1]$} & {$[0.651,1]$} & 17 & 0.574 & {$[0.062,0.939]$} & {$[0.294,1]$} & 17 & 0.580 & {$[0.089,0.939]$} & {$[0.294,1]$} \\
10 & 12 & 0.663 & {$[0.384,1]$} & {$[0.269,1]$} & 11 & 0.613 & {$[0.283,0.901]$} & {$[0.268,1]$} & 13 & 0.631 & {$[0.300,0.957]$} & {$[0.268,1]$} \\
11 & 10 & 0.666 & {$[0.257,1]$} & {$[0.406,1]$} & 3 & 0.657 & {$[0.283,1]$} & {$[0.345,1]$} & 4 & 0.659 & {$[0.290,1]$} & {$[0.345,1]$} \\
12 & 11 & 0.665 & {$[0.275,1]$} & {$[0.384,1]$} & 7 & 0.646 & {$[0.283,0.943]$} & {$[0.360,1]$} & 7 & 0.655 & {$[0.286,0.973]$} & {$[0.360,1]$} \\
13 & 8 & 0.684 & {$[0.328,1]$} & {$[0.407,1]$} & 9 & 0.644 & {$[0.283,0.940]$} & {$[0.352,1]$} & 8 & 0.653 & {$[0.280,0.980]$} & {$[0.352,1]$} \\
14 & 7 & 0.702 & {$[0.462,1]$} & {$[0.344,1]$} & 6 & 0.646 & {$[0.283,0.947]$} & {$[0.353,1]$} & 3 & 0.660 & {$[0.292,0.994]$} & {$[0.353,1]$} \\
15 & 15 & 0.620 & {$[0.114,1]$} & {$[0.366,1]$} & 5 & 0.649 & {$[0.283,0.966]$} & {$[0.349,1]$} & 12 & 0.648 & {$[0.278,0.966]$} & {$[0.349,1]$} \\
16 & 9 & 0.669 & {$[0.430,1]$} & {$[0.248,1]$} & 8 & 0.645 & {$[0.283,0.961]$} & {$[0.337,1]$} & 9 & 0.653 & {$[0.289,0.988]$} & {$[0.337,1]$} \\
17 & 1 & 0.829 & {$[0.464,1]$} & {$[0.853,1]$} & 10 & 0.626 & {$[0.312,0.744]$} & {$[0.515,0.933]$} & 1 & 0.679 & {$[0.452,0.817]$} & {$[0.515,0.933]$} \\
\hline
\end{tabular}

TABle 9: Continuation of Table 8.

\begin{tabular}{|c|c|c|c|c|c|c|c|c|c|c|c|}
\hline \multirow[t]{2}{*}{ Branch } & \multicolumn{3}{|c|}{$\begin{array}{c}\text { Noncooperative game approach. Stage } 2 \\
\text { is the leader }\end{array}$} & \multicolumn{2}{|c|}{$\begin{array}{l}\text { Aggregation } \\
\text { approach of } \\
\text { additive form }\end{array}$} & \multicolumn{2}{|c|}{$\begin{array}{l}\text { Cooperative } \\
\text { game approach }\end{array}$} & \multicolumn{2}{|c|}{$\begin{array}{l}\text { Average } \\
\text { efficiencies }\end{array}$} & \multicolumn{2}{|c|}{$\begin{array}{l}\text { Aggregation } \\
\text { approach of } \\
\text { multiplicative } \\
\text { form }\end{array}$} \\
\hline & System & Stage 2 & Stage 1 & Rank & System & Rank & System & Rank & System & Rank & System \\
\hline 1 & 0.548 & {$[0.083,0.989]$} & {$[1,0.119]$} & 13 & 0.637 & 13 & 0.594 & 17 & 0.579 & 11 & 0.510 \\
\hline 2 & 0.605 & {$[0.285,0.980]$} & {$[1,0.154]$} & 7 & 0.646 & 8 & 0.633 & 13 & 0.604 & 10 & 0.514 \\
\hline 3 & 0.607 & {$[0.288,0.996]$} & {$[0.995,0.15]$} & 8 & 0.644 & 1 & 0.674 & 8 & 0.620 & 5 & 0.553 \\
\hline 4 & 0.608 & {$[0.285,1]$} & {$[0,997,0.148]$} & 2 & 0.649 & 7 & 0.648 & 9 & 0.619 & 6 & 0.551 \\
\hline 5 & 0.559 & {$[0.086,1]$} & {$[1,0.148]$} & 16 & 0.610 & 5 & 0.664 & 10 & 0.611 & 1 & 0.591 \\
\hline 6 & 0.607 & {$[0.281,1]$} & {$[1,0.148]$} & 11 & 0.639 & 11 & 0.609 & 7 & 0.621 & 7 & 0.543 \\
\hline 7 & 0.603 & {$[0.279,0.967]$} & {$[1,0.165]$} & 10 & 0.642 & 15 & 0.576 & 12 & 0.605 & 14 & 0.493 \\
\hline 8 & 0.575 & {$[0.133,1]$} & {$[1,0.169]$} & 17 & 0.575 & 3 & 0.670 & 14 & 0.601 & 3 & 0.557 \\
\hline 9 & 0.580 & {$[0.089,0.939]$} & {$[1,0.294]$} & 12 & 0.638 & 6 & 0.659 & 16 & 0.589 & 12 & 0.500 \\
\hline 10 & 0.780 & {$[0.300,0.957]$} & {$[, 0.863]$} & 14 & 0.633 & 16 & 0.575 & 6 & 0.621 & 13 & 0.495 \\
\hline 11 & 0.788 & {$[0.290,1]$} & {$[!, 0.863]$} & 5 & 0.646 & 4 & 0.669 & 1 & 0.663 & 4 & 0.556 \\
\hline 12 & 0.781 & {$[0.286,0.973]$} & {$[1,0.863]$} & 9 & 0.644 & 10 & 0.612 & 4 & 0.637 & 15 & 0.484 \\
\hline 13 & 0.781 & {$[0.280,0.980]$} & {$[1,0.863]$} & 3 & 0.648 & 2 & 0.672 & 5 & 0.625 & 17 & 0.351 \\
\hline 14 & 0.788 & {$[0.292,0.994]$} & {$[1,0.863]$} & 4 & 0.647 & 9 & 0.629 & 2 & 0.655 & 2 & 0.560 \\
\hline 15 & 0.777 & {$[0.278,0.966]$} & {$[1,0.863]$} & 15 & 0.632 & 12 & 0.595 & 3 & 0.641 & 8 & 0.543 \\
\hline 16 & 0.636 & {$[0.289,0.988]$} & {$[1,0.267]$} & 6 & 0.646 & 17 & 0.551 & 11 & 0.608 & 9 & 0.516 \\
\hline 17 & 0.580 & {$[0.452,0.817]$} & {$[0.933,0.119]$} & 1 & 0.733 & 14 & 0.578 & 15 & 0.601 & 16 & 0.411 \\
\hline
\end{tabular}

considered as the interval for evaluation. Table 7 illustrates the data.

After solving the problem using the models presented in the previous section, the values obtained from the efficiency of the divisions and system as well as their rankings are displayed in Tables 8 and 9. In the first column, the efficiencies and rankings obtained by the CCR model are represented regardless of the cross deficiency and interval data. The last column shows the average efficiencies and rankings obtained through different approaches. Other columns are devoted to the models proposed in the last section.

Although the outputs of the models for each DMU render the minimum and maximum efficiencies, only the average value of the interval is represented in the table as the system efficiency. The end efficiencies of all the approaches are represented in Figure 4.

The results show that the methods of additive, an average of two divisions, cooperative, one-leader division, and multiplicative have the most results close to the noncross mode, respectively.

The farther the efficiencies of the units are, the higher the distinction between them is and the more accurate the final ranking will be. If we use the variance as a scattering index of the efficiencies of the units, the models of average, additive, leader division A, cooperative, multiplicative, and leader division $\mathrm{B}$ have the lowest to highest variance, respectively. 


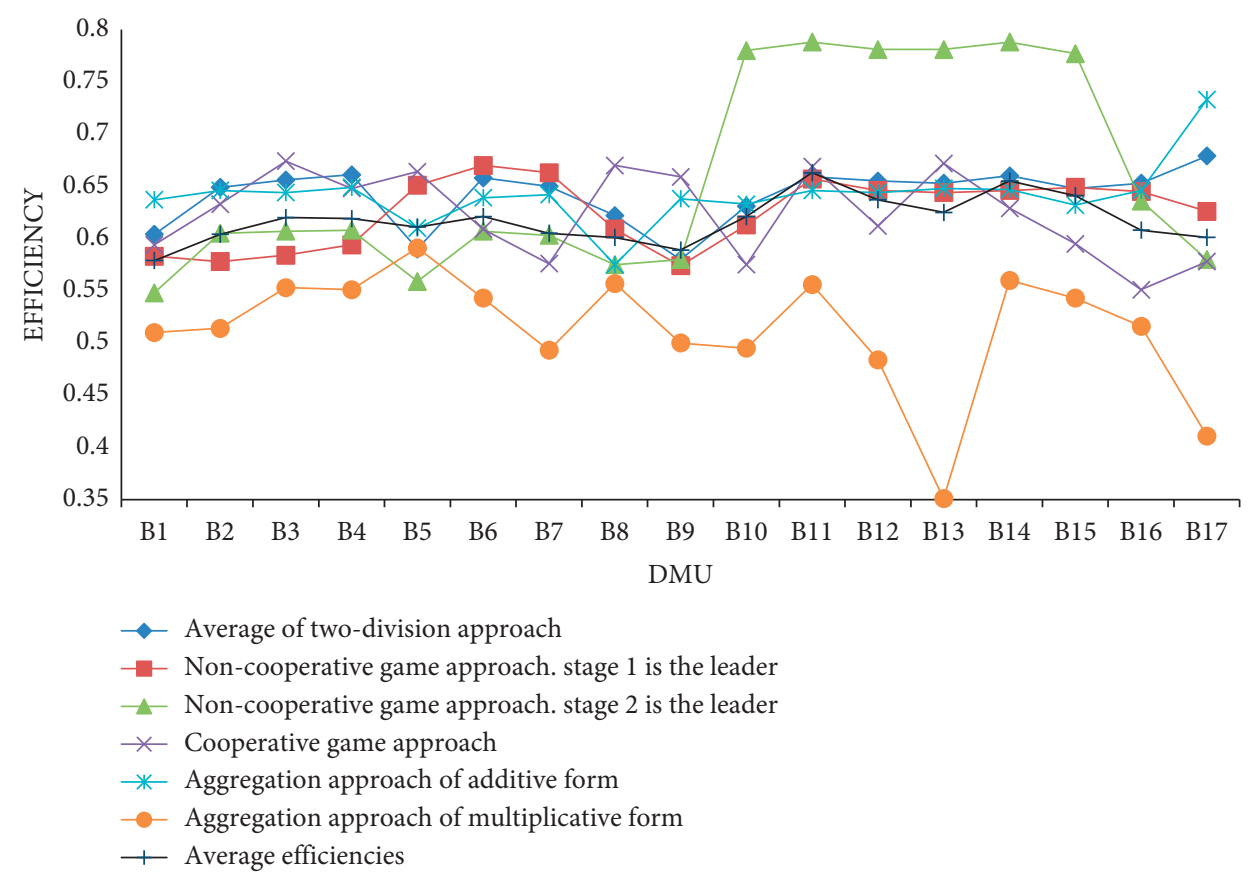

Figure 4: Comparison of the efficiency of the units obtained through different approaches.

The choice of method should be made according to the type of problem. In the two-division average method, the efficiency of both divisions is calculated separately. This model is used for problems where the two divisions are independent of each other. The method in which a section is a leader is used for a situation in which one of the divisions is independent as the leader of the system and the other one is dependent on the leader division. The cooperative approach is used for systems where both divisions are interdependent. The methods cooperative and noncooperative are used more often for supply chain issues. The efficiency of the whole system can be considered as the sum or product of two divisions. For the additive-form method, the weight of each division is calculated as the ratio of the inputs of that division to the total inputs. For the multiplicative-form method, the total efficiency of the system is calculated by multiplying the efficiencies of the divisions. Since the result of multiplying two numbers will be smaller than both of them, the efficiency calculated by this method will be less than that by the other methods.

\section{Conclusion}

This study investigated the cross efficiency models in the NDEA for the interval data uncertainty. The network considered in this study is of general two-stage type. Four linear models and two non-linear models using different approaches of network efficiency were provided. The proposed models were adopted through a real example in the banking industry because of its high compatibility with the general two-stage network. The findings show the closeness of the values of the system efficiency and a wide gap between the rankings obtained through different approaches, making it harder for a decision maker to make final decision. A simple solution would be using the average ranking achieved through different approaches as the final ranking for the purpose of decision making. The calculated values are dependent on the case under investigation, and using a case with higher data dispersion will result in closer output rankings through different approaches and more distinguished efficiency values. The choice of method by the decision maker should be made according to the degree of dependence of the divisions to each other. It is suggested for future research to statistically calculate the divisiondependencies.

There are various challenges in the banking industry which can be addressed by further investigations, including: development of these models for other network systems such as the parallel mode; using other cross efficiency approaches such as aggressive and benevolent; proposing a model for concepts of variable returns to scale or slack-based; as well as using other forms of uncertain data such as fuzzy and probable.

\section{Data Availability}

The data values related to 17 branches of an Iranian bank in Tehran were investigated in this paper. The name of the bank is not mentioned because the data are confidential. Therefore, the use of data in this manuscript is free for everyone.

\section{Conflicts of Interest}

The authors declare that they have no conflicts of interest. 


\section{References}

[1] A. Charnes, W. W. Cooper, and E. Rhodes, "Measuring the efficiency of decision making units," European Journal of Operational Research, vol. 2, no. 6, pp. 429-444, 1978.

[2] R. D. Banker, A. Charnes, and W. W. Cooper, "Some models for estimating technical and scale inefficiencies in data envelopment analysis," Management Science, vol. 30, no. 9, pp. 1078-1092, 1984.

[3] M. J. Farrell, "The measurement of productive efficiency," Journal of the Royal Statistical Society: Series A, vol. 120, no. 3, pp. 253-281, 1957.

[4] A. Charnes and W. W. Cooper, "Programming with linear fractional functionals," Naval Research Logistics Quarterly, vol. 9, no. 3-4, pp. 181-186, 1962.

[5] F. Hosseinzadeh Lotfi, G. R. Jahanshahloo, M. Khodabakhshi, M. Rostamy-Malkhlifeh, Z. Moghaddas, and M. Vaez-Ghasemi, "A review of ranking models in data envelopment analysis," Journal of Applied Mathematics, vol. 2013, Article ID 492421, 20 pages, 2013.

[6] P. Andersen and N. C. Petersen, "A procedure for ranking efficient units in data envelopment analysis," Management Science, vol. 39, no. 10, pp. 1261-1264, 1993.

[7] S. Mehrabian, M. R. Alirezaee, and G. R. Jahanshahloo, “A complete efficiency ranking of decision making units in data envelopment analysis," Computational Optimization and Applications, vol. 14, no. 2, pp. 261-266, 1999.

[8] G. R. Jahanshahloo, A. Memariani, F. H. Lotfi, and H. Z. Rezai, "A note on some of dea models and finding efficiency and complete ranking using common set of weights," Applied Mathematics and Computation, vol. 166, no. 2, pp. 265-281, 2005.

[9] T. Sueyoshi, "Dea non-parametric ranking test and index measurement: slack-adjusted dea and an application to Japanese agriculture cooperatives," Omega, vol. 27, no. 3, pp. 315-326, 1999.

[10] X.-B. Li and G. R. Reeves, "A multiple criteria approach to data envelopment analysis," European Journal of Operational Research, vol. 115, no. 3, pp. 507-517, 1999.

[11] T. R. Sexton, R. H. Silkman, and A. J. Hogan, "Data envelopment analysis: critique and extensions," New Directions for Program Evaluation, vol. 1986, no. 32, pp. 73-105, 1986.

[12] D. K. Despotis, "Improving the discriminating power of dea: focus on globally efficient units," Journal of the Operational Research Society, vol. 53, no. 3, pp. 314-323, 2002.

[13] J. Wu, J. Sun, and L. Liang, "Dea cross-efficiency aggregation method based upon shannon entropy," International Journal of Production Research, vol. 50, no. 23, pp. 6726-6736, 2012.

[14] J. Wu, L. Liang, and F. Yang, "Determination of the weights for the ultimate cross efficiency using shapley value in cooperative game," Expert Systems with Applications, vol. 36, no. 1, pp. 872-876, 2009.

[15] Y. M. Wang and S. Wang, "Approaches to determining the relative importance weights for cross-efficiency aggregation in data envelopment analysis," Journal of the Operational Research Society, vol. 64, no. 1, pp. 60-69, 2013.

[16] Y.-M. Wang and K.-S. Chin, "The use of owa operator weights for cross-efficiency aggregation,” Omega, vol. 39, no. 5, pp. 493-503, 2011.

[17] J. Doyle and R. Green, "Efficiency and cross-efficiency in dea: derivations, meanings and uses," Journal of the Operational Research Society, vol. 45, no. 5, pp. 567-578, 1994.
[18] M. Oral, O. Kettani, and P. Lang, "A methodology for collective evaluation and selection of industrial r\&d projects," Management Science, vol. 37, no. 7, pp. 871-885, 1991.

[19] M. Carrillo and J. M. Jorge, "An alternative neutral approach for cross-efficiency evaluation," Computers \& Industrial Engineering, vol. 120, pp. 137-145, 2018.

[20] F. Li, Q. Zhu, Z. Chen, and H. Xue, "A balanced data envelopment analysis cross-efficiency evaluation approach," Expert Systems with Applications, vol. 106, pp. 154-168, 2018.

[21] Q. Hou, M. Wang, and X. Zhou, "Improved dea cross efficiency evaluation method based on ideal and anti-ideal points," Discrete Dynamics in Nature and Society, vol. 2018, no. 9, Article ID 1604298, 2018.

[22] S. Ang, M. Chen, and F. Yang, "Group cross-efficiency evaluation in data envelopment analysis: an application to taiwan hotels," Computers \& Industrial Engineering, vol. 125, pp. 190-199, 2018.

[23] X. Kuang, "Evaluation of railway transportation efficiency based on super-cross efficiency," in Proceedings of the IOP Conference Series: Earth and Environmental Science, vol. 108, no. Issue, 26 September 2018, Article ID 032049.

[24] F. Li, Q. Zhu, and L. Liang, "Allocating a fixed cost based on a dea-game cross efficiency approach," Expert Systems with Applications, vol. 96, pp. 196-207, 2018.

[25] L. Castelli, R. Pesenti, and W. Ukovich, "A classification of dea models when the internal structure of the decision making units is considered," Annals of Operations Research, vol. 173, no. 1, pp. 207-235, 2010.

[26] C. Kao and S.-N. Hwang, "Efficiency measurement for network systems: it impact on firm performance," Decision Support Systems, vol. 48, no. 3, pp. 437-446, 2010.

[27] C. Kao and S.-T. Liu, "Cross efficiency measurement and decomposition in two basic network systems," Omega, vol. 83, pp. 70-79, 2019.

[28] C. Kao, "Network data envelopment analysis," Springer, vol. 10, pp. 26-33, 2017.

[29] L. Liang, F. Yang, W. D. Cook, and J. Zhu, "Dea models for supply chain efficiency evaluation," Annals of Operations Research, vol. 145, no. 1, pp. 35-49, 2006.

[30] M. Fathollah Bayati and S. Sadjadi, "Two-tier supplier base efficiency evaluation via network dea: a game theory approach," International Journal of Engineering, vol. 29, no. 7, pp. 931-939, 2016.

[31] H. Khademi Zare, H. Hosseini Nasab, A. Ardekani, and M. Fakhrzad, "A robust two-stage data envelopment analysis model for measuring efficiency: considering iranian electricity power production and distribution processes," International Journal of Engineering, vol. 29, no. 5, pp. 646-653, 2016.

[32] D. K. Despotis and Y. G. Smirlis, "Data envelopment analysis with imprecise data," European Journal of Operational Research, vol. 140, no. 1, pp. 24-36, 2002.

[33] D. Akbarian, "A new DEA ranking system based on interval cross efficiency and interval analytic hierarchy process methods," International Journal of Management and Decision Making, vol. 19, no. 3, pp. 344-363, 2020, p.

[34] X. Zhou, Y. Wang, J. Chai, L. Wang, S. Wang, and B. Lev, "Sustainable supply chain evaluation: a dynamic double Frontier network DEA model with interval type-2 fuzzy data," Information Sciences, vol. 504, pp. 394-421, 2019.

[35] F. S. Seyed Esmaeili, M. Rostamy-Malkhalifeh, and F. Hosseinzadeh Lotfi, “Two-stage network DEA model under interval data," Mathematical Analysis and Convex Optimization, vol. 1, no. 2, pp. 103-108, 2020, p. 
[36] Y. Yu, W. Zhu, and Q. Zhang, "DEA cross-efficiency evaluation and ranking method based on interval data," Annals of Operations Research, vol. 278, no. 1, pp. 159-175, 2019.

[37] A. N. Berger and D. B. Humphrey, "Efficiency of financial institutions: International survey and directions for future research," European Journal of Operational Research, vol. 98, no. 2, pp. 175-212, 1997. 